\title{
Four Decades Of African American Portrayals In Magazine Advertising
}

\author{
Thomas H. Stevenson, University of North Carolina at Charlotte, USA
}

\begin{abstract}
This paper examines the frequency of black portrayals as well as the occupations and racial compositions employed in ads depicting blacks in four mass circulation consumer magazines over four decades The portrayal of African Americans in advertising has been of interest to marketers for more than half a century. However, few studies have spanned multiple decades and very few have been extended into the $21^{\text {st }}$ century. This study extends a previous paper (Stevenson 1999) addressing the portrayal of blacks in the consumer print media. Through the use of content analysis, more than 1500 ads were analyzed in these magazines for the years 1975, 1985, 1995, and 2005. Findings indicate that there were significant increases in the numbers of blacks portrayed in the magazines analyzed in this study. It was also determined that where blacks were portrayed in occupational roles, most depictions were "above skilled labor" and that most portrayals utilized mixed peer rather than non-mixed peer depictions. Findings are compared to previous studies, managerial implications are considered, and suggestions for future research are offered.
\end{abstract}

Keywords: Ethnic advertising; minority advertising; content analysis; African American

\section{INTRODUCTION}

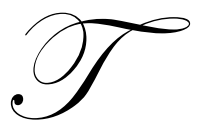

he numerical and economic importance of black Americans as a consumer group continues to increase. In 2005 (the last year of the current study) there were nearly 40 million African Americans in the U.S., representing more than 13 percent of the population, the second largest minority group (U. S. Department of Commerce 2008). Further, the economic impact of African Americans is huge and it is growing rapidly due to significant increases in blacks' buying power. To illustrate, according to the Selig Center at the University of Georgia, African American buying power increased from $\$ 318.1$ billion to $\$ 845.4$ billion from 1990 to 2007; an increase of more than 165 percent. This increase was greater than the 124 percent increase in the buying power of whites and the 134 percent increase in the buying power of all races combined for the same period (www.selig.uga.edu), and these increases are projected to continue.

These increases suggest that from a strategic standpoint, marketers who fail to effectively respond to the African American presence are missing an opportunity, because research has shown that black models may be more effective than whites in communicating with black audiences (Choudhury and Schmid 1974; Gibson 1969). Moreover, other studies have shown that when minority consumers are aware that companies are targeting them they tend to respond better to those companies' ads and products (Cui 1997; Grier and Brumbaugh 1999). Additionally, ignoring for a moment the strategic advantages of targeting African Americans, from a societal point of view appropriate (non-stereotypical) media portrayals can support the upward movement of minorities in society, particularly if stereotypical portrayals are replaced by more realistic representations (Faber, O'Guinn and Meyer 1987). Such portrayals present little risk of negative responses from white consumers since studies have shown that there have been generally positive white audience responses to ads depicting blacks (Avery 2003; Singer 1993; Petroshius and Crocker 1989; Whittler 1989).

Despite these strategic and societal imperatives, research on magazine advertising indicates that historically a small percentage of magazine advertisements were using black models. Sterns et.al. (1987) conducted a study of 1,175 magazine ads, specifically excluding from final tabulation publications such as Ebony and Essence which 
would be expected to have large percentages of black models. They found that only 2.4 percent of the 1,175 ads studied, excluding Ebony and Essence, employed black models. Ortizano (1989) analyzed 2502 magazine ads published in 1984 and found that only five percent of general magazine ads depicted blacks. Zinkhan, Qualls and Biswas (1990) found that the percentage of ads using black models in 1986 was only 4.37 percent. Taylor, Lee and Stern (1995) looked at more than 1600 advertisements from magazines published in 1992 and 1993, and found that 11.4 percent of the advertisements depicted black models. Each of these studies concluded that the representation of African Americans in consumer magazine advertisements trailed their representation in the overall population. Even studies conducted in the late 1990s and into the $21^{\text {st }}$ century, while sometimes finding increases in African American portrayals, still identified problematic portrayals. For example, Plous and Neptune (1997) found that blacks were underrepresented in magazines targeted to whites. On the other hand, Millard and Grant (2006) found that in fashion magazines, the proportion of black women shown was roughly equal to the proportion of blacks in the U. S.

In addition to the study of frequency of appearance of blacks in ads, occupational portrayal and racial composition in ads depicting blacks have also been studied. With regard to occupational portrayal, Cox (1970) found a change from unskilled occupational portrayal to skilled occupational portrayal from 1949-50 to 1967-68. A later update of the Cox article showed a continued increase in the percentage of blacks portrayed at above skilled labor occupations (Zinkhan, Cox and Hong 1986). Humphrey and Schumann (1984) found only 14 percent of blacks portrayed as laborers, but blacks were three times as likely as whites to be portrayed in unskilled occupational roles. Stearns, Unger and Luebkeman (1987) found that occupational skill level of blacks portrayed was no different than that portrayed by whites. Zinkhan, Qualls and Biswas (1990) found that African Americans were depicted in higher status roles in magazine advertisements. A later study of high circulation trade magazines (Stevenson 1992) showed that $53 \%$ of blacks were portrayed as managers/professionals, i.e., at skilled occupational levels.

In looking into the issue of racial composition in magazine advertising, Kassarjian (1969) found a significant decline in racially mixed non-peer ads and an increase in mixed peer ads over the period from 1946 to 1965. Humphrey and Schumann (1984) found that the percent of ads depicting blacks in mixed race peer settings had increased from virtually none in 1950 to 65 percent in 1980. Stempel (1971), in an earlier study on the interaction of blacks and whites in ads, found increases in ads where blacks and whites appeared together. Similarly, Stevenson (1992) found in trade magazine ads that blacks were rarely pictured alone.

Nevertheless, there are those that feel that advertisers have not been aggressive enough in responding to the growing African American presence despite historic pressure from black interest groups to increase the black presence and improve African American role portrayal in ads (Reiss 1983; Joseph 1986); and the issue is still pertinent in the first decade of the $21^{\text {st }}$ century (Harris 2002; Palmer 2001). Even members of the advertising industry have criticized the media for responding too slowly. For example, one survey of marketing and media executives (the majority of whom were white) found that more than half felt that through stereotyping and under representation, advertising media were contributing to racial unrest in the U. S. (Ward 1992).

\section{RESEARCH FOCUS}

The purpose of this study is to extend previous research (Stevenson 1999) regarding magazine advertising portrayals of African Americans forward into the $21^{\text {st }}$ century and to evaluate how contemporary portrayals compare to those of earlier decades. The specific questions examined are:

1. What is the frequency of use of black models in mass circulation magazine advertising and has it changed over the four decade period?

2. What is the racial composition of magazine advertisements portraying blacks and has it changed over the four decade period?

3. What are the occupational portrayals depicted in magazine advertisements portraying blacks and have they changed over the four decade period? 


\section{METHODOLOGY}

The mass circulation consumer magazines selected for this study were Better Homes and Gardens, Reader's Digest, Sports Illustrated, and Time. They were selected because of their availability in bound copies (microfiche and microfilm do not generate reliable content analyses of model race) over the four decade period of the study, 1975-2005, and because of their high circulation and broad segment appeal. Further, because this paper is an extension of a previous paper (Stevenson 1999), they were the publications originally studied. Further the methodology (described below) employed in this study is the same as in the prior paper.

All advertisements in each magazine were content analyzed quarterly for the years 1975, 1985, 1995 and 2005. The issues reviewed were January, March, June and October. These months were selected to avoid issues with abnormally high and non-representative advertising frequencies such as pre-holiday, back-to-school, and so forth. In the case of weekly publications, the week selected for analysis was chosen randomly from the subject month. The magazines reviewed were obtained in North Carolina, thus they could contain variations from issues that would be available elsewhere. No attempt was made to control for this nor was an attempt made to control for duplicate ads within or between publications.

All advertisements that included people in the selected media were viewed. Drawings, cartoons, and pictorial ads not including people were not considered. In each ad containing people, the ad was reviewed to determine the total number of people in the ad, the number of black people in the ad, the occupation portrayed by the black if one or more were present, and the racial composition of magazine advertisements portraying blacks. A total of 1,542 ads portraying people were content analyzed over the four decades of this study.

Occupational portrayal was evaluated as either "above skilled labor" or "below skilled labor," as per Cox (1970) and Kassarjian (1969). The categories used for racial composition included: all black, mixed as peers, mixed as non-peers, or separate picture; and follow those used by Humphrey and Schuman (1984).

Although every attempt was made to be objective in gathering the data for the study, the possibility of observer bias was present. Hence, an independent observer randomly selected and analyzed 154 or 10 percent of the 1,542 advertisements included in the study and 100 percent of the ads depicting blacks. The results of the interjudge reliability tests are shown in Table 1, they are within the standards for observer agreement (Kassarjian 1977).

Table 1

Reliability Of The Content Analysis

\begin{tabular}{lc}
\hline \multicolumn{1}{c}{ Variable } & Percentage Agreement \\
\hline Model race (all ads) & 91 \\
Model race (ads depicting blacks) & 96 \\
Racial composition portrayed (ads depicting blacks) & 87 \\
Occupation portrayed (ads depicting blacks) & 86 \\
\hline
\end{tabular}

\section{FINDINGS}

Table 2 shows that in the initial study (Stevenson 1999) the number of blacks depicted in advertisements portraying people increased from 5.4 percent in 1975, to 8.6 percent in 1985 and to 14.3 percent in 1995 . By 2005 they had increased again to 21.1 percent. Using a difference of proportions test, the changes over the three decades since 1975 were shown to be significant at the .05 level. The increases to 14.3 percent of advertisements portraying blacks in 1995 and to 21.1 percent of ads depicting blacks in 2005 are quite remarkable because they indicate that the a priori population representation standard was exceeded. That is, the 14.3 percent of ads with black models exceeded the African American population percentage of 12.6 percent in 1995; and the 21.1 percent of ads showing blacks in 2005 exceeded the U.S. percent population of African Americans, which was 13.1 percent at that time.

Table 2 also shows the specific numbers of ads depicting people and ads depicting blacks by publication. It can be seen that until 1995, the use of black models in ads in Sports Illustrated increased dramatically in each time 
period while such usage in Better Homes and Gardens remained consistently low. The use of blacks in advertisements in Time and Reader's Digest increased in both 1985 and 1995, but the increase was not as pronounced as the increase in Sports Illustrated. Nevertheless, as late as 1995, Better Homes and Gardens advertisers fell short of the a priori standard of minority representation. By 2005, however, all publications exceeded the standard, with the most dramatic percentage increase being seen in Better Homes and Gardens, a publication which had lagged behind the standard for the previous three decades.

Table 2

Racial Representation In Advertisements By Magazine And Year

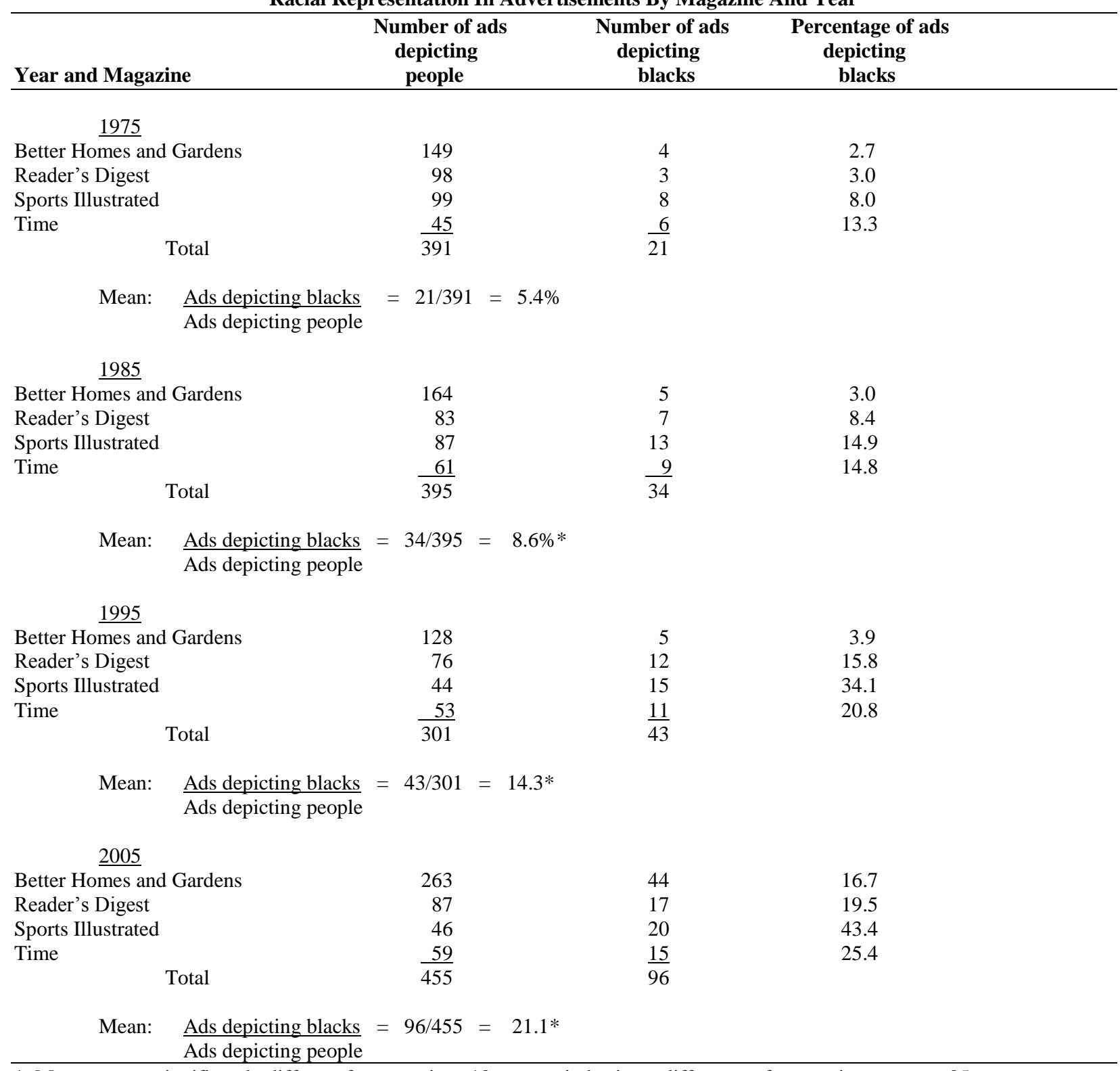

* Mean percent significantly different from previous 10 year period using a difference of proportion test, $\mathrm{p}=.05$.

Table 3 shows the racial composition of ads in which African Americans were portrayed in the publications under review. The decades through 1995 witnessed infrequent use of mixed non-peer ads and the fairly frequent use of mixed peer ads in ads depicting blacks. There was a decrease in the percentage of mixed peer ads in 1985 and 
1995, accounted for primarily by an increase in "all black" ads, not by a large increase in mixed non-peer ads. The findings for 1985 and 1995 suggest a trend away from mixed peer to separate picture or one-race portrayals and this "trend" appears to have continued into 2005. In that year, 56 percent were either separate picture or all black ads; i.e., 56 percent of the ads where blacks were depicted showed no white and black models together in the ad.

Table 3 also shows that most of the magazines in this study used no mixed non-peer ads in the issues included in the sample through 1995. Time was the only publication to use a non-peer portrayal in 1995; it was used only twice, in one case the black model was in the superior role, in the other the white model was superior. By 2005 the use of mixed non-peer ads was more widespread, occurring in three of the four publications reviewed. Nevertheless, in four of the five ads where mixed non-peer portrayals were observed, the higher status role was portrayed by an African American model, not a white model. For example, the school principal was a black female, the students were white. In another instance, the doctor was African American and the patient was white.

Table 3

Racial Mix By Magazine And Year

\begin{tabular}{|c|c|c|c|c|c|c|c|c|c|}
\hline Year and Magazine & $\begin{array}{l}\text { Number of } \\
\text { Black Ads }\end{array}$ & & $\begin{array}{l}\text { Mixed } \\
\text { Peer Ad } \\
\end{array}$ & & $\begin{array}{l}\text { Mixed Non- } \\
\text { Peer Ad }\end{array}$ & & $\begin{array}{l}\text { Separate } \\
\text { Picture }\end{array}$ & & $\begin{array}{l}\text { All } \\
\text { Black }\end{array}$ \\
\hline \multicolumn{10}{|l|}{1975} \\
\hline Better Homes and Gardens & 4 & 4 & $(100 \%)$ & & & & & & \\
\hline Reader's Digest & 3 & 2 & $(67 \%)$ & & & 1 & $(33 \%)$ & & \\
\hline Sports Illustrated & 8 & 6 & $(75 \%)$ & & & 2 & $(25 \%)$ & & \\
\hline Time & $\underline{6}$ & $\underline{3}$ & $(50 \%)$ & & & $\underline{2}$ & $(33 \%)$ & $\underline{1}$ & $(17 \%)$ \\
\hline Total & $\overline{21}$ & $1 \overline{5}$ & $(71 \%)$ & & & $\overline{5}$ & $(24 \%)$ & $\overline{1}$ & $(5 \%)$ \\
\hline \multicolumn{10}{|l|}{$\underline{1985}$} \\
\hline Better Homes and Gardens & 5 & 4 & $(80 \%)$ & & & & & 1 & $(20 \%)$ \\
\hline Reader's Digest & 7 & 4 & $(57 \%)$ & & & 3 & $(43 \%)$ & & \\
\hline Sports Illustrated & 13 & 7 & $(54 \%)$ & & & 2 & $(15 \%)$ & 4 & $(31 \%)$ \\
\hline Time & 9 & $\underline{2}$ & $(21 \%)$ & & & $\underline{6}$ & $(67 \%)$ & $\underline{1}$ & $(12 \%)$ \\
\hline Total & $\overline{34}$ & $1 \overline{7}$ & $(50 \%)$ & & & $1 \overline{1}$ & $(32 \%)$ & $\overline{6}$ & $(18 \%)$ \\
\hline \multicolumn{10}{|l|}{1995} \\
\hline Better Homes and Gardens & 5 & 3 & $(60 \%)$ & & & 1 & $(20 \%)$ & 1 & $(20 \%)$ \\
\hline Reader's Digest & 12 & 4 & $(33 \%)$ & & & 5 & $(42 \%)$ & 3 & $(25 \%)$ \\
\hline Sports Illustrated & 15 & 6 & $(40 \%)$ & & & 1 & $(7 \%)$ & 8 & $(53 \%)$ \\
\hline Time & $\underline{11}$ & $\underline{4}$ & $(36 \%)$ & $\underline{2}$ & $(18 \%)$ & $\underline{1}$ & $(9 \%)$ & $\underline{4}$ & $(36 \%)$ \\
\hline Total & $\overline{43}$ & $1 \overline{7}$ & $(40 \%)$ & $\overline{2}$ & $(5 \%)$ & $\overline{8}$ & $(19 \%)$ & $1 \overline{6}$ & $(37 \%)$ \\
\hline \multicolumn{10}{|l|}{2005} \\
\hline Better Homes and Gardens & 44 & 13 & $(30 \%)$ & $2 *$ & $(5 \%)$ & 6 & $(14 \%)$ & 23 & $(52 \%)$ \\
\hline Reader's Digest & 17 & 7 & $(41 \%)$ & $2 *$ & $(12 \%)$ & 1 & $(6 \%)$ & 7 & $(41 \%)$ \\
\hline Sports Illustrated & 20 & 10 & $(50 \%)$ & & & 2 & $(10 \%)$ & 8 & $(40 \%)$ \\
\hline Time & $\underline{15}$ & $\underline{6}$ & $(40 \%)$ & $\underline{1}$ & $(7 \%)$ & & & $\underline{8}$ & $(53 \%)$ \\
\hline Total & $\overline{96}$ & $3 \overline{6}$ & $(38 \%)$ & $\overline{5}$ & $(5 \%)$ & 9 & $(9 \%)$ & $4 \overline{6}$ & $(48 \%)$ \\
\hline
\end{tabular}

*Note: Blacks in superior role

Table 4 shows the occupations depicted by blacks in the ads studied. During the four decades observed there was relatively little change in the occupational skill level of blacks. In all but one year studied, 90 percent or more of the portrayals by blacks were "above skilled labor" (as defined by Cox 1970 and Kassarjian 1969). Further, in the year 1985 the percentage was only slightly below 90 percent $(88.2 \%)$. Although there were some fluctuations within specific role categories, the essential finding was that blacks were not any more likely than whites to be shown routinely in levels "below skilled labor." 


\section{DISCUSSION}

The increasing use of blacks in advertisements depicting people accelerated in the decades beyond 1975, increasing significantly in the three following decades. The result was that by 1995 the percentage of black presence in ads, 14.3 percent, widely exceeded the 12.6 percent African American presence in the U. S. population in 1995 and it did so again in 2005, 21.1 percent presence versus 13.1 percent population representation (U. S. Department of Commerce 2008). Thus, it would appear that blacks were fairly represented in 1995 and 2005, at least in comparison to their proportion in the total population. Therefore, the trend toward greater use of blacks in advertisements, which was noted by Kassarjian (1969), Stutts and Pride (1980), and Taylor, Lee and Stern (1995), continued in the mid-1990s and beyond in consumer magazines with broad segment appeal (i.e., those appealing to both blacks and whites). The dramatic increases from 1985 to 1995 and from 1995 to 2005 perhaps suggest that concerns about African American percentage representations are now moot, but continuing monitoring and attention to a broader range of media vehicles will be required to determine if this statement holds true over the long term.

The racial compositions portrayed in ads do not support past claims of black interest groups that blacks are portrayed disadvantageously. No mixed non-peer ads were found in the two earlier time periods studied. Even in 1995 and 2005 the percentage of mixed non-peer ads was small, never more than five percent of the ads studied. Further, where mixed non-peer ads did occur, the lower status role was likely to be occupied by a white model, not an African American. Moreover, the majority of ads in the time periods through 1995 portrayed racial compositions best described as mixed peer. It was not until 2005 that the majority of ads shifted from mixed peer to "all black." This is a marked change from the situation found earlier in trade magazine ads where blacks were rarely pictured alone (Stevenson 1992). Perhaps the later increase in "all black" ads found in this study, indicates that a potential "white backlash," which was first mentioned in the early 1970's (Cagley and Cardozo 1970) and later by Avery (2003), was unfounded or that the danger of such reactions had passed. The nearly ten fold increase in such portrayals from 1975 to 2005 seems to bear this out. In general, the findings regarding racial composite in ads where African Americans are portrayed appear to reinforce the observation of Bush et al. (1980) who stated that blacks" "role portrayal has moved very near one of equality on many dimensions" (p. 486).

Table 4

Occupations Portrayed By Blacks By Year

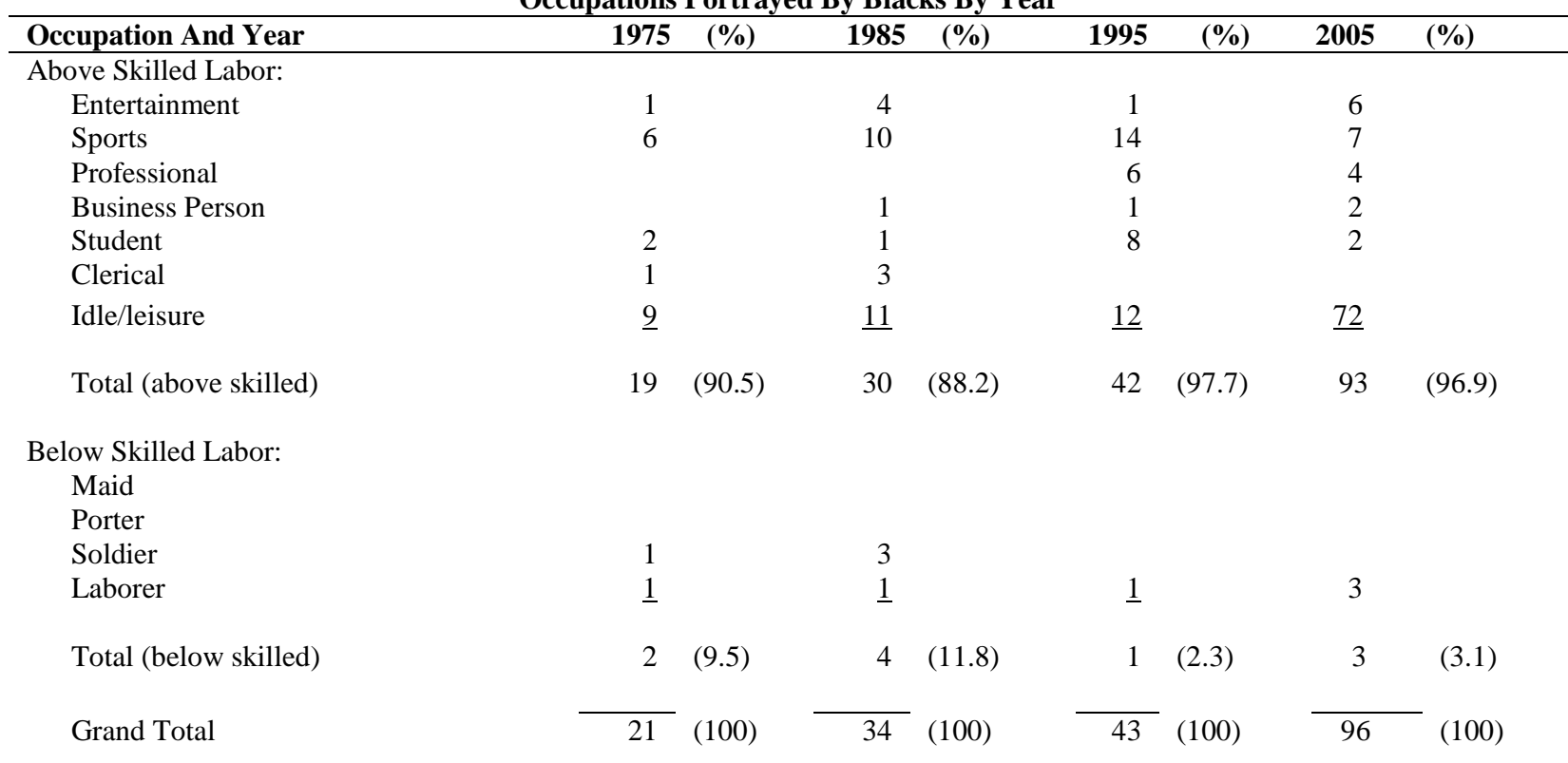

Black occupational portrayals were not shown to have varied significantly over the four decades of this study. In all periods the vast majority of black portrayals were above skilled labor and the occupations and activities 
depicted by blacks tended to reflect middle-class surroundings and values. This observation is especially apparent regarding ads in 2005 where there was a remarkable increase in portrayals in leisure/idle categories, that is, where no specific occupation was implied. Interestingly however, there was a decline in black portrayals in sports settings in 2005. This is in contrast to an earlier observation (Cox 1970) that blacks are frequently portrayed as athletes. However, the findings of this study do lend credence to a more recent statement by Stearns, Unger and Luebkeman (1987) that "advertisers have apparently been sensitive to the obvious variable of occupational role" (p. 201).

The overall results revealed by this longitudinal study are consistent with others that have shown that there has been progress in crafting ads that should meet the expectations of the booming African American market. What is remarkable about the results of this study is that they show that by 1995 and beyond, the advertisements in this group of consumer magazines vastly exceeded the a priori percentage representation standard; a standard that prior to the decade of the 1990s was approached but never met. These findings ought to be of interest to both advertisers and racial interest groups. For advertisers, it suggests that attention to advertising portrayals that reflect the size and sensitivities of a large and growing market segment is important if marketers wish to reach these segments and avoid potential criticism and lost sales. For minority interest groups, studies such as this provide useful benchmarks for assessing the effects of their efforts to secure proportional representation in the media.

It should be noted however, that there are potential limitations to this study. First, it analyzed only advertisements in four magazines, thus results cannot be generalized to all print media nor do they apply to electronic media. Second, the study data were collected using content analysis; thus the study can only identify what was done, not why the images were selected or how target audiences responded. Future studies of audiences and advertisers, rather than the ads themselves, would be necessary to provide this information. This would provide interesting depth to the issue of racial representation in advertising. Additionally, because the U.S. population of Hispanics now exceeds that of African Americans and because it is the fastest growing ethnic segment, focus on content analysis of ad representations of Hispanics is timely. And as the Internet has grown in importance as an advertising medium, racial portrayals in that channel could also be investigated.

\section{CONCLUSION}

The purpose of this study was to examine the use of black models in mass circulation consumer magazine advertising over four decades. The time frame selected was intended to provide a multi-decade longitudinal study which would extend into the first decade of the $21^{\text {st }}$ century. Results of the study suggest that the number of blacks in advertisements has steadily increased and that the rate of increase accelerated beyond 1985. The occupations depicted and racial compositions in black ads have changed somewhat, but over time the sensitive areas of mixed non-peer ads and occupational depictions, have moved in a direction that does not suggest negative stereotypes.

\section{AUTHOR INFORMATION}

Thomas H. Stevenson is the Cullen Professor of Marketing the University of North Carolina at Charlotte. He received his B.S. and M.B.A. degrees from Syracuse University; his Ph.D. in Marketing is from Case Western Reserve University. His research interests include consumer and business-to-business promotion, ethnic marketing, and the integration of marketing with other business functions. His recent publications have appeared in Business Horizons, California Management Review, Industrial Marketing Management, the International Business and Economics Research Journal, the Journal of Advertising, the Journal of Current Issues and Research in Advertising, the Journal of International Marketing and the Journal of Business Ethics.

\section{REFERENCES}

1. Avery, D. R. (2003). Reactions to Diversity in Recruitment Advertising - Are Differences Black and White? Journal of Applied Psychology, 88 (4), 672-679.

2. Cagley, J. W. and Cardozo, R. N. (1970). White Responses to Integrated Advertising. Journal of Advertising Research, 10 (April), 35-39.

3. Choudhury, P. K. and Schmid, L. S. (1974). Black Models in Advertising to Blacks. Journal of Advertising Research, 19-22. 
4. Cox, K. (1970). Changes in Stereotyping of Negroes and Whites in Magazine Advertisements. Public Opinion Quarterly, (Winter), 603-606.

5. Cui, G. (1997). Marketing Strategies in a Multi-Ethnic Environment. Journal of Marketing Theory and Practice, 1, (5), 122-134.

6. Faber, R. J., O’Guinn, T. C. and Meyer, T. P. (1987). Televised Portrayals of Hispanics: A Comparison of Ethnic Perceptions. International Journal of Intercultural Relations, 11, 155-169.

7. Gibson, D. P. (1969). \$30 Billion Negro. New York: MacMillan Co.

8. Grier, S.A. and Brumbaugh, A.M. (2001). Social Dimensions of Consumer Distinctiveness: The Influence of Social Status of Group Identity and Advertising Persuasion. Journal of Advertising, 28, (1), 79-93.

9. Harris, J. R. (2002). Old Tricks Won’t Lure Af-Am Consumers. Marketing News, 36 (July 22), 21.

10. Humphrey, R. and Schuman, H. (1984). The Portrayal of Blacks in Magazine Advertisements: 1950-1982. Public Opinion Quarterly, 44, 551-563.

11. Kassarjian, H. H. (1977). Content Analysis in Consumer Research. Journal of Consumer Research, 4, 8-18.

12. (1969). The Negro and American Advertising, 1946-1965. Journal of Marketing Research, 2939.

13. Millard, J. E. and Grant, P.R. (2006). The Stereotypes of Black and White Women in Fashion Magazine Photographs: The Pose of the Model and the Impression She Creates. Sex Roles, 54, (9/10), 658-673.

14. Ortizano, G. L. (1989). Visibility of Blacks and Whites in Magazine Photographs. Journalism Quarterly, 66 (Autumn), 718-722.

15. Palmer, J. (2001). It's Not Hip to be Square: Mindful of Cultural Blundering, Marketers Slowly Target African-Americans, Promo, 14 (February), 21-26.

16. Petroshius, S. M. and Crocker, K. E. (1989). An Empirical Analysis of Spokesperson Characteristics on Advertisement and Product Evaluations. Journal of the Academy of Marketing Science, 17 (Summer), 217 225.

17. Plous, S. and Neptune, D. (1997). Racial and Gender Roles in Magazine Advertising. Psychology of Women Quarterly, 21, (4), 627-645.

18. Reiss, C. (1983). Black Media Association Cites Offensive Ads. Advertising Age, (September 19), 78.

19. Singer, B. D. (1983). The Case for Using "Real People" in Advertising. Business Quarterly, (Winter), 32-37.

20. Stearns, J. M., Unger, L. S. and Luebkeman, S. G. (1987). The Portrayal of Blacks in Magazine and Television Advertising. AMA Educators' Proceedings, Susan R. Douglas et al., eds., Chicago: American Marketing Association, 198-203.

21. Stempel, G. H., III (1971). Visibility of Blacks in News and News-Picture Magazines. Journalism Quarterly, 48 (Summer), 337-339.

22. Stevenson, T. H. (1992). A Content Analysis of the Portrayal of Blacks in Trade Publication Advertising. Journal of Current Issues and Research in Advertising, 14, (1), 67-74.

23. (1999), "The African-American Presence in Consumer Magazine Advertising: A Three Decade Longitudinal Study," Proceedings of the American Society of Business and Behavioral Sciences, 6, 4, 122 131.

24. Taylor, C. R., Lee, J. Y. and Stern, B. B. (1995). Portrayals of African, Hispanic, and Asian Americans in Magazine Advertising, American Behavioral Scientist, 38 (February), 608-621.

25. U. S. Department of Commerce, Bureau of the Census (2008). Statistical Abstract of the United States, (December).

26. Ward, A. (1992). What Role Do Ads Play in Racial Tension? Advertising Age, 63, (August 10), 1, 35.

27. Whittler, T. E. (1991). The Effects of Actors' Race in Commercial Advertising: Review and Extension. Journal of Advertising, 20, (1), 54-60.

28. _ (1989). Viewers' Processing of Source and Message Cues in Advertising Stimuli. Psychology and Marketing, 6, (4), 287-309.

29. Zinkham, G. M., Cox, K. K. and Hong, J. W. (1986). Changes in Stereotypes: Blacks and Whites in Magazine Advertisements. Journalism Quarterly, 63, (3), 568-570.

30. Zinkhan, G. M., Qualls, W. J. and Biswas, A. (1990). The Use of Blacks in Magazine and Television Advertising: 1946 to 1986. Journalism Quarterly, 67 (Autumn), 547-554. 